\title{
Splenic Arteriovenous Fistula with Pseudoaneurysm
}

\section{Cagri Yurtsever ${ }^{1}$ Murat $\mathrm{Ak}^{2}$}

${ }^{1}$ Department of Radiology, Sultan Abdulhamid Han Teaching Hospital, Istanbul, Turkey

${ }^{2}$ Department of Radiology, University of Pittsburgh, Pittsburgh, Pennsylvania, United States

J Gastrointestinal Abdominal Radiol ISGAR 2021;4:247-248.

A 24-year-old male patient with a history of laparoscopic splenectomy presented to the outpatient clinic with pain and fullness in the left upper quadrant of the abdomen. Physical examination and laboratory results were unremarkable. Contrast-enhanced computed tomography (CT) showed aneurysm with a maximum diameter of $30 \mathrm{~mm}$ on the distal part of the tortuous splenic artery and splenic arteriovenous fistula and early opacification of the splenic vein ( - Fig. 1A, B). Three-dimensional CT reconstruction revealed aneurysm and connection between the splenic artery and vein ( - Fig. 1C). Aneurysm was interpreted in favor of pseudoaneurysm in the case with a splenectomy history. Splenic artery pseudoaneurysm with splenic arteriovenous fistula infrequently occurs as a complication of splenectomy. Rupture and portal hypertension are potential complications.
Address for correspondence Murat Ak, University of Pittsburgh, 5115 Centre Avenue, Pittsburgh, PA 15232, United States (e-mail: akm@upmc.edu; yurtsevercagri@gmail.com).

This patient subsequently underwent endovascular intervention, treated with coil embolization, and has continued to do well on clinical follow-up visits.

\section{Discussion}

Occurrence of a splenic artery pseudoaneurysm with an arteriovenous fistula is a rare complication might be seen after splenectomy. ${ }^{1}$ Rupture is the major risk of splenic artery pseudoaneurysm and mortality is almost inevitable if it rupture. ${ }^{2}$ Also, untreated splenic arteriovenous fistulas may cause portal hypertension. ${ }^{1}$ Therefore, splenic pseudoaneurysm must be treated without delay regardless of their size, even if there is no bleeding due to high-rupture risk. ${ }^{2,3}$ Contrast-enhanced CT, CT angiography, and splenic

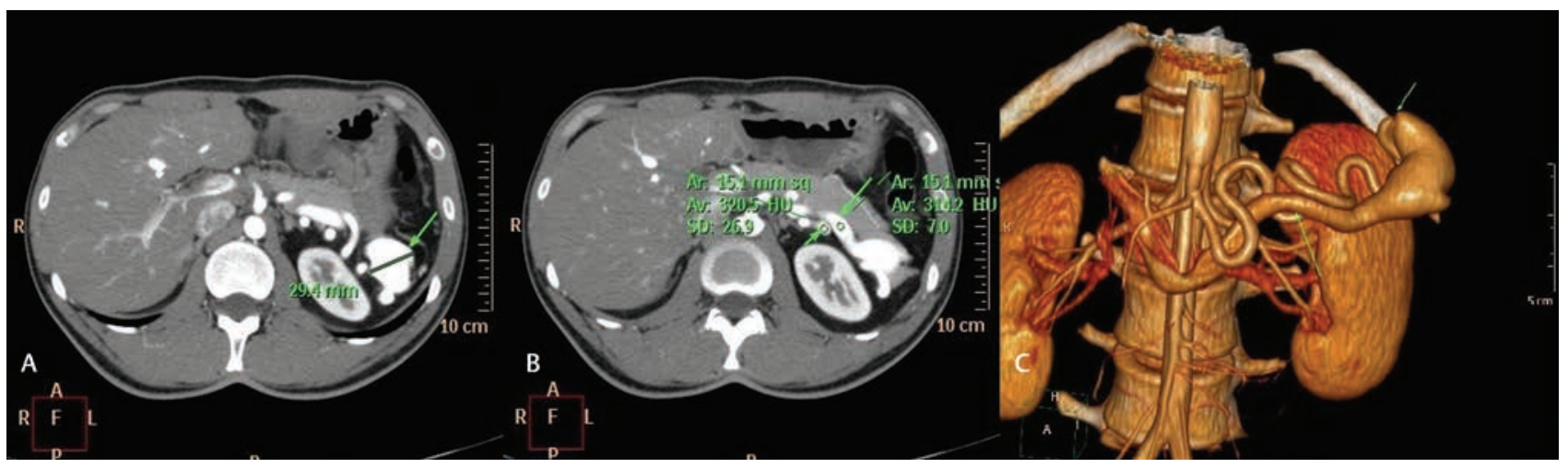

Fig. 1 (A-C) Contrast-enhanced computed tomography (CT) showed aneurysm with a maximum diameter of $30 \mathrm{~mm}$ on the distal part of the tortuous splenic artery and splenic arteriovenous fistula and early opacification of the splenic vein. (C) Three-dimensional CT reconstruction revealed aneurysm and connection between the splenic artery and vein. A, anterior; Av, average; F, front; L, left; P, posterior; R, right; SD, standard deviation.

published online

April 17, 2021
DOI https://doi.org/

$10.1055 / \mathrm{s}-0041-1726656$ ISSN 2581-9933
(C) 2021. Association for Helping Neurosurgical Sick People.

This is an open access article published by Thieme under the terms of the Creative Commons Attribution-NonDerivative-NonCommercial-License, permitting copying and reproduction so long as the original work is given appropriate credit. Contents may not be used for commercial purposes, or adapted, remixed, transformed or built upon. (https://creativecommons.org/licenses/by-nc-nd/4.0/).

Thieme Medical and Scientific Publishers Pvt. Ltd. A-12, 2nd Floor, Sector 2, Noida-201301 UP, India 
arteriogram are valuable for diagnosis. Conventionally, splenic pseudoaneurysm was managed by surgery, but endovascular approach became the mainstay treatment in recent years. $^{2,3}$ As a conclusion, diagnosis and treatment of splenic pseudoaneurysm and arteriovenous fistula are crucial to avoid associated fatal risks.

\section{Conflict of Interest}

None declared.

\section{References}

1 Gartside R, Gamelli RL. Splenic arteriovenous fistula. J Trauma 1987;27(6):671-673

2 McDermott VG, Shlansky-Goldberg R, Cope C. Endovascular management of splenic artery aneurysms and pseudoaneurysms. Cardiovasc Intervent Radiol 1994;17(4):179-184

3 Guillon R, Garcier JM, Abergel A, et al. Management of splenic artery aneurysms and false aneurysms with endovascular treatment in 12 patients. Cardiovasc Intervent Radiol 2003;26(3):256-260 